\title{
Base Sheet Generation for 1:24,000-Scale Maps
}

\author{
By John E. Findley
}

Open-File Report 93-352 


\section{Contents}

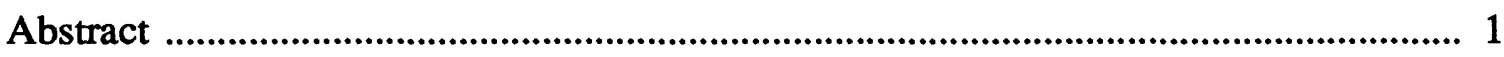

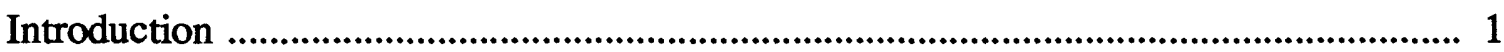

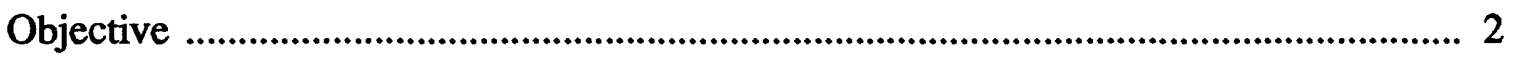

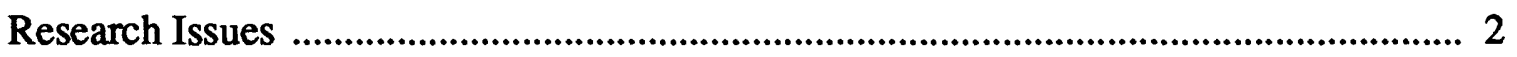

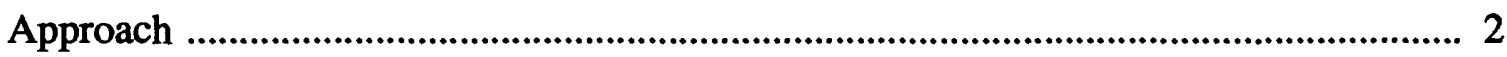

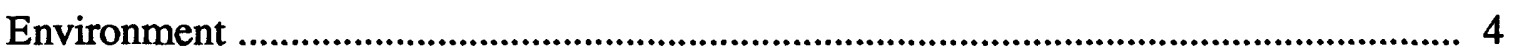

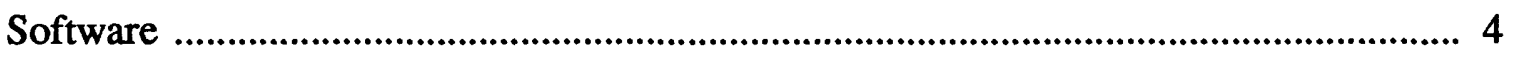

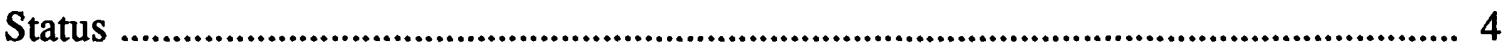

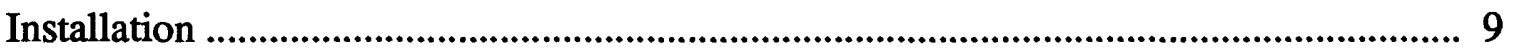

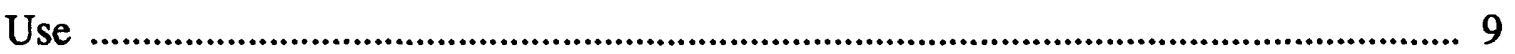

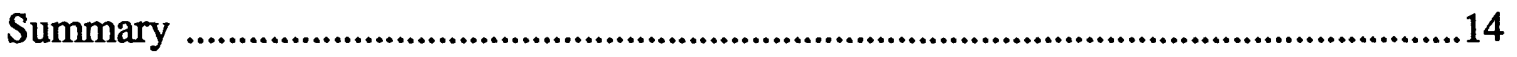

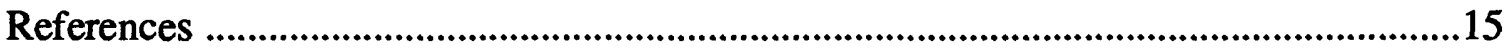

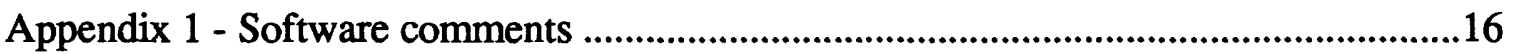

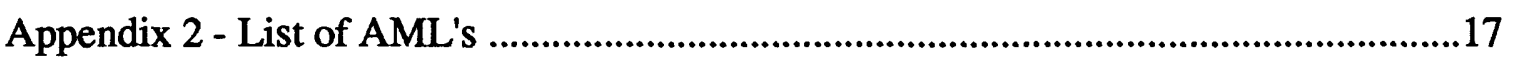

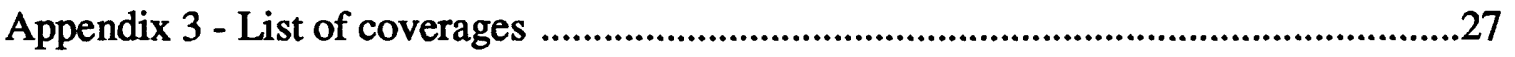




\begin{abstract}
The U.S. Geological Survey (USGS) is making the transition from traditional cartographic production procedures to an automated process primarily using commercially available, off-the-shelf technologies. During this transition, the USGS developed a prototype system as a proof-of-concept model that can produce 1:24,000scale neatline templates.

The starting point for map production is a base sheet containing precise geodetic and geographic information. This project uses geographic information system technology to generate automatically the neatline, graticule, rectangular coordinate system grid, and associated labels for 7.5-minute topographic maps. Written in the Arc Macro Language, the project relies on ARC/INFO software to process, project, and overlay coverages.

Procedures within the model validate user input, incorporate USGS graphic standards, produce neatlines using either North American Datum of 1927 or 1983 horizontal datum, automatically place coordinate labels, and resolve labeling conflicts. The product is a graphic file that can be submitted to various editing and plotting systems used at the USGS. This project provides an accurate cartographic framework and map template for ARC/INFO users.
\end{abstract}

\title{
INTRODUCTION
}

The U.S. Geological Survey (USGS) supports Federal, State, and public interests by providing diverse cartographic, geographic, and remotely sensed data products and services. The paper or analog map has been an integral product of the USGS for many years. The USGS produces 16 standard map products; however, the 1:24,000-scale map is the primary map product and a principal tool for management decisions. This map series is complete for the United States and conveys accurate cultural and topographic information.

To meet increasing national needs and user demands, the USGS is undergoing a transformation from an organization that provides conventional topographic information to an organization that provides map products derived from digital data. Since the mid-1970's, the USGS has collected and archived digital cartographic data from its standard maps as part of the National Mapping Program. This evolution has resulted in procuring new systems for production. With these new computer-based tools the USGS is developing innovative digital procedures to create graphic map products.

Any use of trade, product, or firm names is for descriptive purposes only and does not imply endorsement by the U.S. Government. 


\section{OBJECTIVE}

The objective of this project is to use geographic information systems (GIS) techniques to develop, as a proof-of-concept model, a map template representing the neatline, graticule, rectangular coordinate system grid, and associated labels for 1:24,000-scale graphic production. This map template is a starting point or geographic reference for USGS map production. Proceeding from this accurate base sheet, cartographic features from digital line graph data are added to the template to create a complete 7.5-minute graphic map. Map templates use either Lambert Conformal Conic or Transverse Mercator projections for the North American Datum of 1927 (NAD27). In the United States, the Transverse Mercator projection is used for the State Plane Coordinate System for States with a predominantly north-south extent (Snyder, 1987). Lambert Conformal Conic projections are used for States with an east-west extent. USGS 1:24,000-scale maps use the Universal Transverse Mercator (UTM) projection for the North American Datum of 1983 (NAD83).

Written using the Arc Macro Language (AML), the prototype model relies on ARC/INFO software and cartographic capabilities to process, project, and overlay coverages (ESRI, 1991b). The base sheet plotting procedures are menu driven and require minimal user interaction. The menus also validate user input. The procedures incorporate USGS graphic standards, produce neatlines using either the NAD27 or NAD83, automatically place coordinate labels (USGS, 1992), and resolve labeling conflicts. The final product is an ARC/INFO graphic file that can be submitted to plotting systems used at the USGS. The model provides an accurate cartographic framework and map template that incorporates National Mapping Program standards.

\section{RESEARCH ISSUES}

The project offered the USGS an opportunity to investigate issues concerning GIS technology and map production techniques. Can GIS technology be used as effectively for cartographic processing? Can GIS technology incorporate established graphic standards? Does ARC/INFO software possess these capabilities? Can it offer the reliability and accuracy to replace existing production software? Is GIS software flexible enough to handle not only standard map products, but also special or thematic maps? Lastly, can such a system be made user friendly?

\section{$\underline{\text { APPROACH }}$}

The base sheet plotting model uses ARC/INFO for cartographic processing and the AML to construct a cartographically correct graphic product. Figure 1 illustrates how the model links functionally related tasks to individual AML's. This approach is logical and allows easier updating and testing of AML's. This approach also logically organizes processes and procedures. Coverages are generated; are projected to the proper datum, spheroid, and 
projection; and are clipped or erased to the proper tick lengths. The product is an ARC/INFO graphic file containing line symbology and collar information that can be displayed interactively or submitted to any plotter supported by ARC/INFO software.

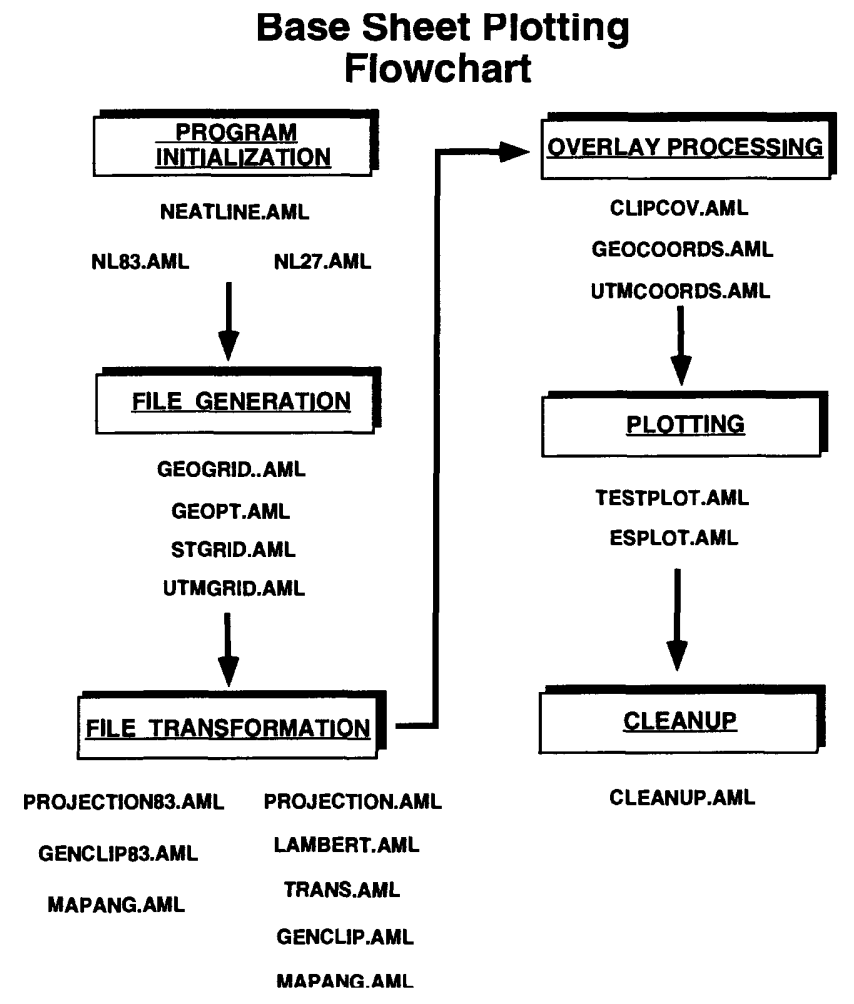

Figure 1. Flow chart for the Base Sheet Plotting Program.

One goal for the model is to make it as user friendly as possible. To accomplish this, menus are used that simplify and streamline user interaction. User input consists of only four items: the quadrangle name, the southeast coordinates for the quadrangle, the datum, and the primary (and if necessary, the secondary, tertiary, and quaternary) State plane zones. Cartographic standards (USGS, 1984) are imbedded within the appropriate AML's and reflect graphic specifications for standard 1:24,000-scale graphics.

Positional accuracy is a concern for map users. In the specifications for neatline generation, a 0.003 -inch tolerance is used. This translates to 6 feet or 1.83 meters in map units. 


$$
\begin{array}{ll}
\text { Example: } & 24000^{\prime \prime} \times 0.003^{\prime \prime} / 12^{\prime}=6 \text { feet } \\
& 24000^{\prime \prime} \times 0.003^{\prime \prime} / 39.37^{\prime}=1.83 \text { meters }
\end{array}
$$

In addition, if the model uses the TESTPLOT.AML, (ARC commands, model AML's, and menus are capitalized), lineweights, tick lengths, and symbology will reflect USGS graphic standards for 1:24,000-scale maps (USGS, 1984). Neatlines are 0.005 inch, UTM ticks are 0.002 inch, and State plane ticks are 0.003 inch. Whether using the TESTPLOT.AML or ESPLOT.AML, geographic graticule ticks are 0.10 inch in length. UTM and State plane ticks are 0.12 inch in length ( 0.02 inch inside the neatline and 0.1 inch outside).

The model is an alternative to existing software for generating 1:24,000-scale neatline templates. The procedures are reliable, improve system control and software maintenance, and are easy to use. ARC/INFO users will find that the AML routines and procedures can be modified easily to meet their specific needs.

\section{ENVIRONMENT}

The software is designed to run on Data General workstations operating under AViiONDG/UX 5.4.1 and using ARC/INFO version 6.1. The model has not been fully evaluated using ARC/INFO version 6.1.1.

\section{SOFTWARE}

The software is written in the AML. All routines and menus can be modified to be compatible with past and newer versions of ARC/INFO. Although the software runs using ARC/INFO version 6.1.1, it has not been tested thoroughly.

The AML's perform a number of tasks based on user input and use ARC/INFO to GENERATE, PROJECT, CLIP, and ERASE coverages to produce neatline, graticule, and collar information. All coverages and operations use double precision (32-bit real numbers) to ensure accuracy.

\section{$\underline{\text { STATUS }}$}

The current program creates an ARC/INFO plot file, in either NAD83 or NAD27 coordinates, with the following collar information:

o The neatline with graticule ticks representing geographic coordinates

o Geographic coordinate labels 
o Graticule intersection ticks within the quadrangle

o Graticule intersection ticks representing the geographic datum shift for the quadrangle

o Up to four State plane coverages and coordinate ticks

o UTM coordinate ticks and labels

o A bar scale in miles and kilometers

Special instructions and supplementary information are included in Appendix 1. Appendix 2 provides a guide to each AML, including their function, variables, and output. Appendix 3 provides a complete list of coverages created by the model.

\section{Coordinate text labels}

The model features automatic coordinate placement and conflict resolution between geographic and UTM coordinate labels. Figure 2 provides an example of geographic and UTM text placement. Corner geographic text uses 8-point Univers Medium (ARC/INFO text font 94021$)$ and is placed 0.08 inches (160 feet or 48.768 meters) from the neatline, and 0.04 inches ( 80 feet or 24.384 meters) elsewhere along the neatline (USGS, 1992). UTM text is placed 0.04 inches from the neatline (USGS, 1992). A point is a text measurement equal to $1 / 72$ of an inch, therefore 8 points is equal to a text size of 0.111 inches $(8 / 72=0.111)$. A text file named unimed8.txt is included to label geographic text. It was created in ARCPLOT using the following commands:

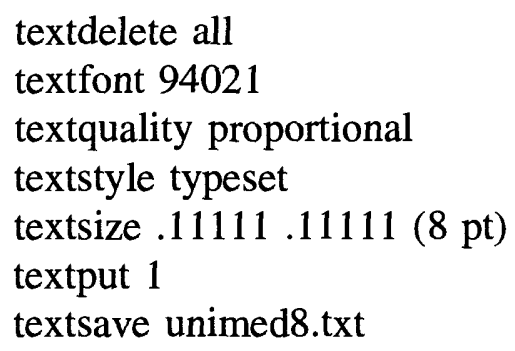

The last phase for labeling and detecting conflicts between geographic, UTM, and State plane coordinates is not complete. However, the same methods used to resolve geographic and UTM text conflicts can be applied for State plane coordinate labels. A unimed7.txt text set is included for State plane labels (see fig. 2). 


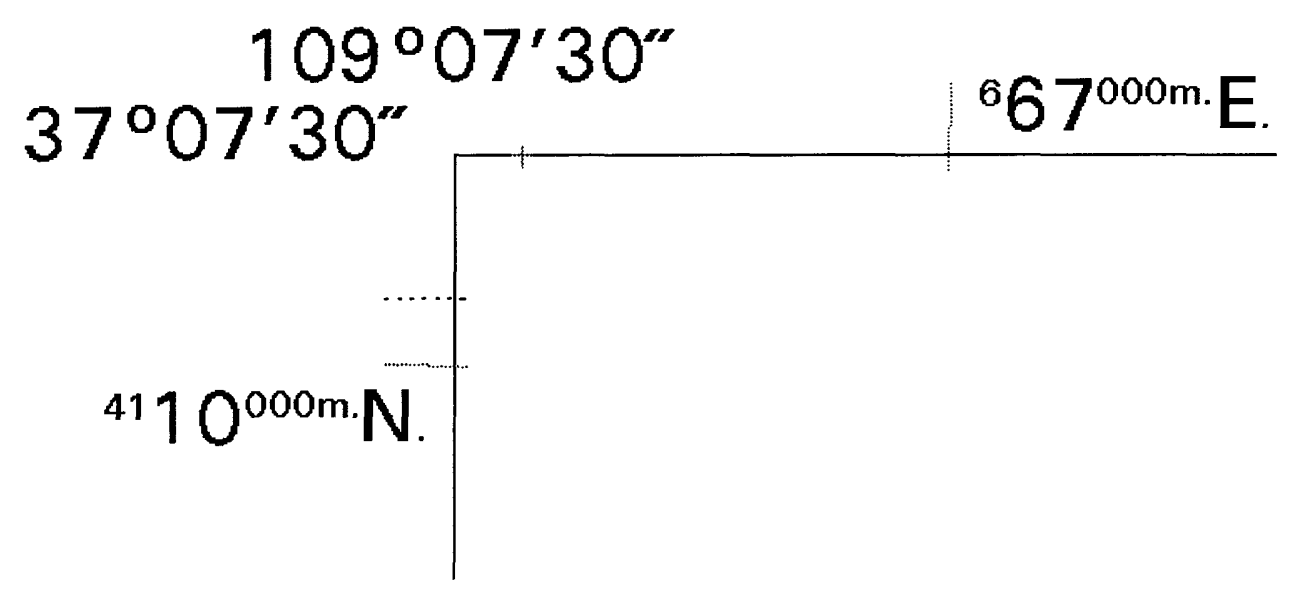

Figure 2. An example of geographic and UTM coordinate text placement in the northwest corner. Also shown is line symbology for UTM and quaternary State plane ticks.

\section{$\underline{\text { Alaska maps }}$}

Alaska 1:24,000 and 1:25,000-scale maps vary in longitudinal size. Routines to handle the diversity of Alaska maps are not complete.

\section{Grid generation}

The model generates UTM and State plane grids. These grids are projected, transforming their original coordinates to either Lambert Conformal Conic, Transverse Mercator, or UTM projections. The model captures the original grid coordinates (prior to projecting them) to ensure that they are available for text labeling. This is done by calculating State or UTM values as text files with the PROJECT command and by using these values as line identification numbers to GENERATE the grid coverages. ARC/INFO cover-ids are later moved to an INFO attribute and used for coordinate labeling. Appendix 1 provides instructions for generating a full UTM grid. 


\section{$\underline{\text { INFO files }}$}

Although ARC/INFO contains a comprehensive library of projection capabilities, specially designed INFO files are used containing State plane parameters specific to either the NAD27 (Snyder, 1987) or the NAD83 (Stem, 1991). Table 1 provides examples. This approach compensates for earlier ARC/INFO versions that could not project State coverages using NAD83 parameters - version 6.1 can. The INFO files also ensure that exact projection parameters for State plane systems are used. In addition, the INFO files include collar information for the State name (USGS, 1980) and State map unit (USGS, 1991).

Table 1. Random sample of the PROJ83.TAB INFO file showing State plane projection parameters and collar textual information.

\begin{tabular}{|c|c|}
\hline \multicolumn{2}{|l|}{3} \\
\hline ST_ZONE & $=3151$ \\
\hline FIPS_ZONE & $=201$ \\
\hline PROJECTION & $=$ transverse \\
\hline STANDARD_P1 & $=$ \\
\hline STANDARD_P2 & $=$ \\
\hline C_MERIDIAN & $=-1101000$ \\
\hline LAT_ORIGIN & $=310000$ \\
\hline SCALE_FACTOR & $=0.999900$ \\
\hline FALSE_E & $=213,360.0000$ \\
\hline FALSE_N & $=0.0000$ \\
\hline ST_NAME & $=(A R I Z)$. \\
\hline UNITS_83 & $=$ METERS \\
\hline 14 & \\
\hline ST_ZONE & $=3451$ \\
\hline FIPS_ZONE & $=501$ \\
\hline PROJECTION & $=$ lambert \\
\hline STANDARD P1 & $=394300$ \\
\hline STANDARD_P2 & $=404700$ \\
\hline C_MERIDIAN̄ & $=-1053000$ \\
\hline LAT_ORIGIN & $=392000$ \\
\hline SCALE_FACTOR & $=0.000000$ \\
\hline FALSE_E & $=914,401.8300$ \\
\hline FALSE_N & $=304,800.6100$ \\
\hline ST_NAME & $=($ COLO $)$ \\
\hline UNITS_83 & $=$ IFEET \\
\hline
\end{tabular}

$\underline{\text { UTM text sets }}$

USGS 1:24,000-scale maps use UTM coordinates that contain superscript text. Therefore, special text sets are included with the model for UTM text. The UTM text file uses text font 94021 (Univers Medium), combines both 8- and 4-point text, and takes advantage of the TEXTSYMBOL in ARCPLOT to replicate the UTM coordinate strings on USGS maps. 
The utm.txt text file was created using the following ARCPLOT commands:

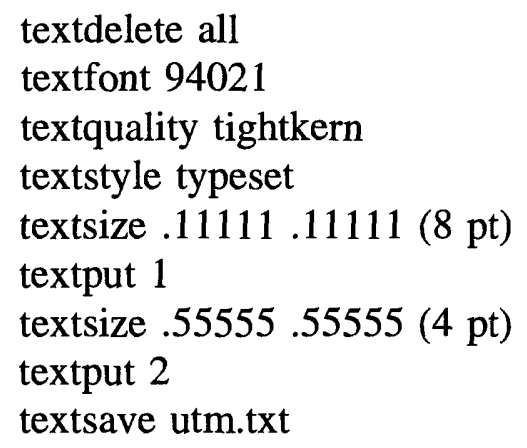

\section{$\underline{\text { Menus }}$}

Menus ensure correct user input and greatly improve the reliability and control of the programs. Designing a series of menus requires a comprehensive understanding of input requirements, the level of user expertise (to make user decisions simple), AML function and method (how it is done), and the AML processing sequence (what needs to be done first, second, and so on). The model applies error-checking routines to ensure that user input is consistent with program needs.

\section{$\underline{\text { Spheroid parameters }}$}

USGS 1:24,000-scale maps include ticks representing horizontal differences between datums (USGS, 1989). The NAD27 uses calculations based on the Clarke 1866 spheroid to represent the shape of the earth. The NAD83 uses calculations from satellite observations - spheroid GRS80. The differences between the datum ticks and the neatline reflect, in part, the differences in these measurements. To plot this, the model projects covers using only the spheroid parameter (not the datum parameter). ARC/INFO version 6.1 allows this (ESRI, 1991), but future versions may not (see appendix 1).

The following prj file generated for an NAD83 UTM neatline illustrates the absence of the datum parameter.

$\begin{array}{ll}\text { Projection } & \text { UTM } \\ \text { Zunits } & \text { NO } \\ \text { Units } & \text { METERS } \\ \text { Spheroid } & \text { GRS } 1980 \\ \text { Xshift } & 0.0000000000 \\ \text { Yshift } & 0.0000000000 \\ \text { Parameters } & \\ -75300.000 & /^{*} \text { longitude } \\ 39450.000 & / * \text { latitude }\end{array}$




\section{$\underline{\text { Registration }}$}

The model includes bullseyes and crosshairs for the registration of color separates.

\section{INSTALLATION}

A 3.5-inch high-density floppy disk is supplied containing all the AML's, menus, text sets, and INFO files. Users are advised to place AML's and the menus in a single directory. The NEATLINE.AML is set up to run using two directories. One directory contains the AML's, menus, INFO files, and text files. The other directory is used as a work area. Users must remember to change the .apath (line 76) and .mpath (line 77) in the NEATLINE.AML. However, users can create a directory structure and modify the NEATLINE.AML to reflect their organizational system and structure by changing the .apath, .mpath, and .return variables.

The user must also be certain that the PROJ83.TAB and PROJ27.TAB INFO files can be accessed within the directory containing the AML's. This requires importing the ARC/INFO export files.

Example: IMPORT INFO proj83tab.e00 proj83.tab

IMPORT INFO proj27tab.e00 proj27.tab

\section{$\underline{\text { USE }}$}

The program is menu driven and requires minimal input by the user. It is essential that the user know the correct State zone(s) that occur within the quadrangle. This may require an examination of NOAA's "Index of State Plane Coordinate Zone Codes" (NOAA, 1982, 1988) for the NAD27 and the NAD83 to locate a specific State zone within a State. Originals for both are available by contacting:

Director, National Geodetic Information Center

National Ocean Service

Rockville, MD. 20852

To run the program users should:

1. Check the NEATLINE.AML to ensure that the .AMLPATH, .MENUPATH, and work area variables are set correctly.

2. Change directories to the work area. 
3. Set the display environment at the system level. Example: setenv DISPLAY resdgw3:0

Also, to preview the ARC/INFO graphics file, users MUST reverse the graphics window to white. This will allow the display of black lines and text on a white background.

Example: setenv CANVASCOLOR WHITE

4. Start ARC/INFO and set \&term 9999.

5. Run the NEATLINE.AML from the work area directory.

Example: \&r ../aml_dir/neatline proj_a

After completion, users can preview the ARC/INFO graphics file by using the DRAW command at the ARC prompt.

Example: DRAW < graphics file > 9999,2.

The NEATLINE.AML displays a sequence of menus that provide the program with the Southeast geographic coordinate for the quadrangle, the datum to be used, and up to four State Plane zones. The NEATLINE.AML then passes this information to the next level of AML's, which in turn process the data.

The INPUT.MENU is used to input the Southeast geographic coordinate value. It includes an error-checking routine (longcheck.aml and latcheck.aml) to ensure that the coordinates are the integer values and the proper length and conform to standard coordinate values ( $00^{\prime \prime}$ or 30 "). Hitting the enter key passes the coordinate values to the error-checking routines. A backspace key clears text. An EXECUTE button passes the information to the program and exits the menu. The menu also contains a QUIT button to exit the menu and the NEATLINE.AML in case of a mistake. The INPUT.MENU is shown in figure 3.

The DATUM.MENU sets the \%.datum\% variable to either 27 or 83 . The menu also includes a QUIT button to exit the menu. Selecting either of the datum buttons continues the process and passes the user to the next menu. The DATUM.MENU is shown in figure 4 .

The OTHERSTATES.MENU sets variables indicating the number of State plane zones to be referenced. Like the previous menus, an EXECUTE button passes the information to the program and the QUIT button exits the menu and the NEATLINE.AML. Included also is a RESET button, which resets all the checkbox buttons in case of user error. The OTHERSTATES.MENU is shown in figure 5. 


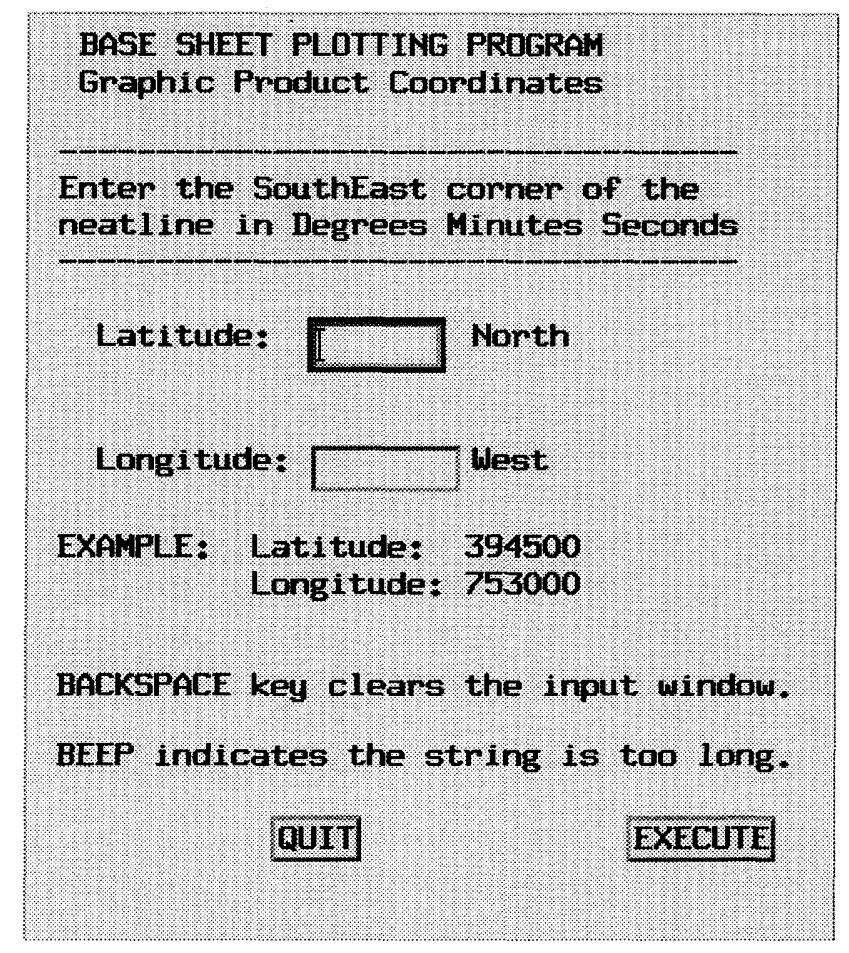

Figure 3. The INPUT.MENU

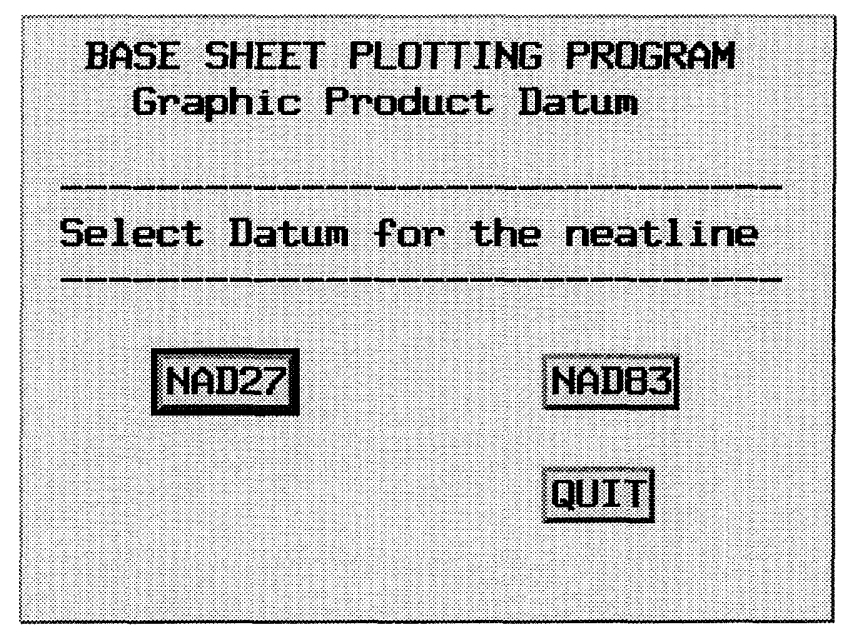

Figure 4. The DATUM.MENU 
The STATE27.MENU or STATE83.MENU sets variables for each State plane zone. Users select sequentially the primary, secondary, tertiary, and quaternary State plane zones. A QUIT button is available on each individual State menu to exit the menu and NEATLINE.AML in case of a mistake. Executing the STATE27.MENU, STATE83.MENU (for States with one State zone), or the individual State menus completes user input and initiates processing. Figure 6 shows the STATE83.MENU and figure 7 shows the VA.MENU.

BASE SHEET PLOTTING PROGRAM State Plane Zones

How many State Plane Coordinate Systems for this quadrangle?

Dne (1) state

- Two (2) states

- Three (3) states

$\square$ Four (4) states

RESET QUIT EXECUTE

Figure 5. The OTHERSTATES.MENU 


\begin{tabular}{|c|c|}
\hline \multicolumn{2}{|c|}{$\begin{array}{l}\text { BASE SHEET PLoTT ING PROERAM } \\
\text { State Plane Zones }\end{array}$} \\
\hline \multicolumn{2}{|c|}{$\begin{array}{l}\text { Select the PRTMARY } \\
\text { coordinate system }\end{array}$} \\
\hline Alabana & Nebraska \\
\hline Alaske & Nevadal \\
\hline Arizona & New Uamgshire \\
\hline Arkansas & New Jersey] \\
\hline California & New Mexica \\
\hline Ealorado & Mew Yorld \\
\hline Connecticut & North Carol ina] \\
\hline Delaware & North Dakota \\
\hline Florida & Ghid: : \\
\hline Eeorgia & Okliahona \\
\hline Hawai in & Oregon \\
\hline I clahal & Pennsy I vania \\
\hline I 11 inuis & Rhode Island] \\
\hline Indiana & South Caralina \\
\hline Iowa & Sguth Dakota \\
\hline Kansas & Tennessed \\
\hline Kentucky & Texas: \\
\hline L oui isiana & Ittah \\
\hline Haine & Vernont \\
\hline Maryiand & Virginia \\
\hline Hassachusetts & Hashington \\
\hline Michigan current & Ulest Virginia \\
\hline Michigan 0Id & Uisconsin \\
\hline Minnesota & Uyoming \\
\hline Mississippi & Puerto Rice \\
\hline Missoura & Virgin Islands \\
\hline Montanal & \\
\hline
\end{tabular}

Figure 6. The STATE83.MENU 


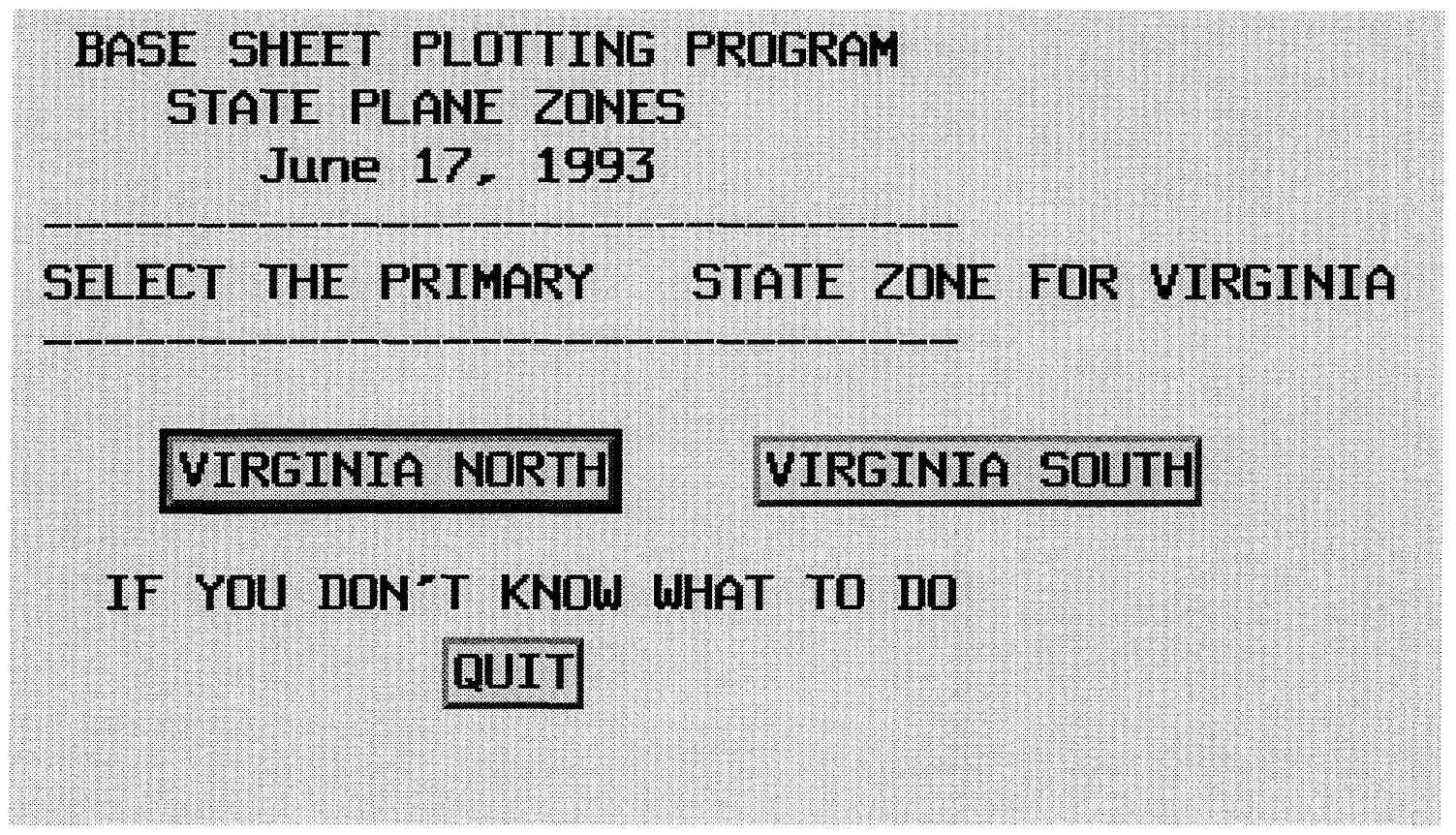

Figure 7. The VA.MENU

\section{SUMMARY}

The project successfully demonstrated that GIS technology can be used for cartographic processing in a production environment. A contemporary GIS software program such as ARC/INFO offers reliability, flexibility, and the capability to position geographic and cartographic features accurately for map production.

In addition, the project achieved several significant accomplishments. It demonstrated the versatility of the ARC/INFO software and the AML by developing a simple, easy-to-use interface, which provides greater system control for modifications and allows direct control over maintenance and operation. The project furnished the means to test USGS datum transformation procedures in conjunction with the Environmental Systems Research Institute to ensure conformance to USGS techniques. Lastly, it developed automated text labeling and text resolution routines for coordinates using ARC/INFO AML's.

The software has limitations. Unique software characteristics are discussed in appendix 1. First, the program can be slow, depending on the number of State plane zones selected and the user workstation environment. To GENERATE, PROJECT, and CLIP topologically structured ARC/INFO coverages can take approximately 10 minutes. Second, the software does not process Alaska maps. Last, the software does not label State plane coordinates. 
The model developed alternative 1:24,000-scale neatline procedures that ensure reliability, improve system control and software maintenance, and are easy to use. If necessary, experienced ARC/INFO users will find that the AML procedures easily can be modified to meet specific needs.

\section{REFERENCES}

Environmental Systems Research Institute (ESRI), 1991a, ARC command references, v. II, July 1991, Table-4, State Plane Zones, and Table-5, FIPS Zone Codes.

1991b, Map projections \& coordinate management, July 1991, p. B-1 - C-5.

Snyder, J.P., 1987, Map projections - a working manual: U.S. Geological Survey Professional Paper 1395, p. 51-56.

Stem, J.E., 1991, State Plane Coordinate System of 1983: NOAA Manual NOS NGS 5.

U.S. Department of Commerce, National Oceanic \& Atmospheric Administration, 1982, Index of State plane coordinate (SPC) zone codes.

U.S. Department of Commerce, National Oceanic \& Atmospheric Administration, 1988, Index of State plane coordinates (SPC) zone codes (NAD 1983).

U.S. Geological Survey, 1980, Abbreviations and word compounds: National Mapping Program Topographic Instructions - chapter 4I2, p. 6-12, (draft).

U.S. Geological Survey, 1984, Publication symbols (metric unit maps), book 5, standards for 1:24,000- and 1:25,000-scale quadrangle maps: National Mapping Program Supplemental Technical Instruction, p. 5-2 - 5-29.

U.S. Geological Survey, 1989, Implementation of North American Datum of 1983 (NAD 83) on National Mapping Division graphic products: National Mapping Program Supplemental Technical Instruction - 89-2-C, p. 1-3.

U.S. Geological Survey, 1991, Labeling of State Plane Coordinate Systems (SPCS) on primary series maps of the National Mapping Division: National Mapping Program Supplemental Technical Instruction - 91-3-C, p. 1-6.

U.S. Geological Survey, 1992, 1:24,000-scale style sheet: National Mapping Program Supplemental Technical Instruction, (draft). 


\section{APPENDIX 1}

Appendix 1 contains additional explanations, suggestions, comments, and problems relevant to the base sheet model.

1. Comments and statements are included in many of the AML's. These were used for tracking the progress of the AML's and for error checking. They may be removed.

2. Comment statements should not be removed from the NL27.AML and NL83.AML until users are fully satisfied with the program. Using the CLEANUP.AML leaves only primary ARC/INFO coverages and the graphic files. The CLEANUP.AML is commented out and will not run.

3. Users are recommended to set an ARC/INFO watch file before running NEATLINE to track the procedures.

Example: \&watch <watch file $>$

To disable a watch file type: \&watch \&off.

4. Users may have to edit the GEOCOORDS.AML text label routine. Data Generals use the ALT 0 sequence to produce a degree symbol. Using the vi editor, an ALT 0 translates into 1260. Copying these AML's sometimes causes the ALT 0 sequence to be read as a four-character text string of 1260 . If this happens, the 1260 text string, and not the degree symbol, will appear in the graphics file.

5. Later versions of ARC/INFO will provide a full complement of Souvenir fonts. If they are not available, users may wish to consider purchasing them.

6. FIPSZONE 2500 for Montana does not work on ARC/INFO version 6.1.

7. According to Environmental Systems Research Institute, version 6.1 does not allow the PROJECT command to evoke a spheroid to spheroid change without using a datum parameter. However, the program does just that and uses this technique to create the neatline. If this changes in later versions, the PROJECT routine must be modified and may require using the PROJ83.TAB INFO file.

8. A full UTM grid can be used instead by:

Clipping \%.COVER\%_UTMGRID with \%.COVER\%_UTM83 for NAD83 datum; or, Clipping \%.COVER\%_UGRIDL or \%.COVER\%_UGRIDT with \%.COVER\%_NLT or $\% . C O V E R \% \_N L L$ for NAD27 datum. Be sure to add the full UTM grid coverage name to ESPLOT.AML or TESTPLOT.AML.

9. The State plane and UTM tick lengths are created using USGS mapping standards of 240 feet or 73 meters. The lengths of the ticks may vary according to the grid angle 
in relation to the ST_CLIP and ST_ERASE coverages. Clipping or erasing these grids can delete ticks that exceed the tolerances set in CLIPCOV2.AML. Although this error has been corrected, users still may encounter this problem and will have to modify the tolerances for each coverage in the CLIPCOV2.AML.

10. The 3.5 high-density disk contains the DG_TAR.FIL and README files.

DG_TAR.FIL is in a tar format. Tar is a unix command that saves and restores files. It stands for tape file archiver and is a common file transfer format between unix systems. The DG_TAR.FIL contains all files necessary to execute base sheet generation. Users should refer to the README file for tar retrieval instructions as well as additional user information.

The base sheet generation files also are avialable through InterNet and users can obtain them using the File Transfer Protocol (ftp). Ftp instructions are included in the README file.

Example:

ftp resdgs3

username: anonymous

password: anonymous

cd /var/ftp/public/neat

get README

mget *.aml

mget *.menu

mget *.e00

mget *.fil

mget *.txt

bye

Users also may copy just the DG_TAR.FIL file.

ftp resdgs3

username: anonymous

password: anonymous

$\mathrm{cd} / \mathrm{var} / \mathrm{ftp} /$ public/neat

type binary

get DG_TAR.FIL

bye 


\section{APPENDIX 2}

The following contains the primary AML's used in the Base Sheet Plotting Program. It also provides an outline that traces the method and routines used to produce neatline graphics. The function, any global variables, and output for each AML are included. All covers and files are created using double precision.

\section{NEATLINE.AML}

Function:

o Runs the INPUT.MENU, DATUM.MENU, OTHERSTATES.MENU, STATE27.MENU, and STATE83.MENU to acquire the southeast latitude and longitude, the datum, and all State plane zones

o LONGCHECK and LATCHECK.AML's run error-checking routines to ensure coordinate input for INPUT.MENU

o Sets paths to work areas

Global variables:

o $\%$.cover\% - project cover name

o $\quad \%$.lat $\%$ and $\%$.long\% - SE latitude and longitude generated by the INPUT.Menu

o $\quad \% . q 1 \%, \% . q 2 \%, \% . q 3 \%, \% . q 4 \%$ - .TRUE.,.FALSE. switches for State planes

o $\%$.datum $\%$ - sets a value for the NAD83 or NAD27

o $\%$.state $1 \%, \%$.state $2 \%, \%$.state $3 \%, \%$.state $4 \%$ - integer values for either State plane zones (NAD27) or FIPS zones (NAD83)

o $\quad \%$.apath\%, \%.mpath\%, \%.return\% - work area variables

2. NL27.AML

Function:

o Controls the flow and operational sequence for NAD27 graphics.

o In order, the NL27.AML makes calls to the following AML's:

ST1_SEARCH.AML

ST2_SEARCH.AML

ST3_SEARCH.AML

ST4_SEARCH.AML

GEOGRID.AML 


\section{GEOPT.AML \\ STGRID.AML \\ UTMGRID.AML \\ PROJECTION.AML \\ CLIPCOV2.AML \\ CLEANUP.AML}

Global variables:

o $\%$.st1_units $\%, \%$.st2_units\%, \%.st3_units\%, \%.st4_units\% - all NAD27 State plane map units are set to feet

o $\%$.longpoint $\%$, \%.latpoint $\%$ - coordinate values used for projecting UTM covers

o $\quad \%$.selong $\%, \%$.selat $\%, \%$.swlong $\%, \%$.swlat $\%, \%$.nelong $\%, \%$ nelat $\%$, $\%$.nwlong $\%, \%$.nwlat $\%$ - coordinate values used for generating the initial neatline (geographic), State plane, and UTM covers

Output:

o Creates \%.cover\%_geo - the initial neatline cover.

o Creates \%.cover\%_tic83 - the external ticks representing the NAD83

2A. NL83.AML

Function:

o Controls the flow and operational sequence for NAD83 graphics

o In order, the NL83.AML runs the following AML's:

ST1_SEARCH.AML

ST2_SEARCH.AML

ST3_SEARCH.AML

ST4_SEARCH.AML

GEOGRID.AML

GEOPT.AML

STGRID.AML

UTMGRID.AML

PROJECTION.AML

CLIPCOV.AML

CLEANUP.AML

Global variables:

o $\%$.longpoint $\%$, \%.latpoint\% - coordinate values used for projecting UTM covers 
o $\quad \%$. selong\%, \%.selat $\%, \%$. swlong\%, \%.swlat $\%, \%$.nelong\%, $\%$. nelat $\%$, $\%$. nwlong $\%$, \%.nwlat $\%$ - coordinate values used for generating the initial neatline (geographic), State plane, and UTM covers

Output:

o Creates \%.cover\%_geo - the initial neatline cover

o Creates \%.cover\%_tic83 - the external ticks representing the NAD83

2B. ST1_SEARCH.AML

ST2_SEARCH.AML

ST3_SEARCH.AML

ST4_SEARCH.AML

Function:

o Checks for the existence of primary, secondary, tertiary, and quaternary States

o Sets required variables and runs either the STATE27.MENU or STATE83.MENU

Global variables:

o $\quad \%$.nu\%, \%.num\%, \%.TEXT1\% - set for specific State zones

3. GEOGRID.AML

Function:

o Generates a geographic grid in decimal degrees with lines every 2'30" (0.04166667 decimal degrees)

o Densifies grid lines (grain 0.015)

o Adds the following attributes to either the PROJ27.TAB or PROJ83.TAB INFO file:

DEG

MIN

SEC

Output:

o Creates the \%.COVER\%_GGRID in decimal degrees based on the latitude and longitude attribute values taken from PROJ27.TAB or PROJ83.TAB 
3. GEOPT.AML

Function:

o Generates a geographic point cover representing internal map ticks. This approach is considered more accurate than using grid intersections from GEOGRID.AML. Additionally, the AML projects the \%.COVER\%_GPT point coverage to the NAD83 and creates \%.COVER\%_GPT83. The $\% . C O V E R \%$ GPT will be projected to the NAD27 in either the LAMBERT.AML or TRANS.AML

Output:

o Creates a \%.COVER\%_GPT cover

o Creates the \%.COVER\%_GPT83 cover

4. STGRID.AML

Function:

- Generates up to four oversized State grids

Grids generated in the NAD27 use 10,000 feet intervals in survey feet. Grids generated in NAD83 use survey feet $(10,000$ feet intervals), meters $(2,500$ meter interval), or international feet (10,000 international feet intervals). An international foot is 0.000002 smaller than the survey foot

o Projects the $\%$.swlong\% and \%.swlat\% variables into the SWGEOTICS file. The SWGEOTICS file is used to create the S1TICS, S2TICS, S3TICS, or S4TICS files.

o Runs the ST1FILE.AML (and if applicable, ST2FILE.AML, ST3FILE.AML, and ST4FILE.AML). These AML's generate grid files for each State plane zone.

o Densifies the \%.COVER\%_S2GRD, \%.COVER\%_S3GRD, and $\% . C O V E R \% \_S 4 G R D$ coverages (grain 1000)

o Adds the STATE_VAL item to the \%.COVER\%_1GRD, \%.COVER\%_S2GRD, $\% . C O V E R \%$ S3GRD, and \%.COVER\%_S4GRD covers. The STATE_VAL item is calculated to equal the cover-id value

Global variables:

o $\% . S 1 \_X O R I G \%, \% . S 1 \_Y O R I G \%, \% . S 1 \_Y A X I S \%, \% . S 2 \_X O R I G \%$, $\% . S 2 \_Y O R I G \%, \% . S 2 \_Y A X I S \%, \% . S 3$ _XORIG\%, \%.S3_YORIG\%, $\% . S 3 \_Y A X I S \%, \% . S 4 \_X O R I G \%, \% . S 4 \_Y O R I G \%$, AND \%.S4_YAXIS\% used to generate specific State grids 
Output:

o Generates the \%.COVER\%_S1GRD, \%.COVER\%_S2GRD, $\% . C O V E R \% \_S 3 G R D$, and the \%.COVER\%_S4GRD coverage for each State

All are oversized grids. The \%.COVER\%-ID's for each arc within the coverage carry the proper $\mathrm{X}$ or $\mathrm{Y}$ State coordinate value

\section{UTMGRID.AML}

Function:

- Generates a UTM coverage

Creates an oversized UTM grid (1,000 meter interval for the NAD27 or 2,500 meter interval for the NAD83)

o Projects the \%.swlong\% and \%.swlat\% variables into the SWUTMCOORDS file. The SWUTMCOORDS file is used as a starting point for creating a UTM grid

o Runs the UTMFILE.AML to create the UTMCOORDS.FIL file

o Densifies \%.COVER\%_UGRID (grain 3)

o Adds a UTM_VAL item to the \%.COVER\%_UGRID coverage and calculates the item to equal the \%.COVER\%_UGRID-ID

Global variables:

o \%.UTM_XORIG\%,\%.UTM_YORIG\%, and \%.UTM_YAXIS\% - used in the UTMFILE.AML to generate the UTMCOORDS.FIL

\section{Output:}

o Generates the \%.COVER\%_UGRID coverage. The oversized grid coverage includes the UTM_VAL attribute, which contains the proper X or Y UTM coordinate value for that arc

6. PROJECTION.AML and PROJECTION83.AML

Function:

o Projects coverages into the proper projection. PROJECTION.AML will project to either Lambert Conformal Conic or Transverse Mercator; PROJECTION83.AML will project to UTM

o Extracts projection parameters from the PROJ27.TAB or PROJ83.TAB INFO files 
o Runs the TRANS.AML or LAMBERT.AML (for the NAD27) to project the geographic, UTM, and State grids into either of the projections

o Runs the GENCLIP.AML or GENCLIP83.AML that creates CLIP and ERASE coverages

Global variables:

o \%.SCALE_FACTOR\%, \%.C_MERIDIAN\%, \%.LAT_ORIGIN\%, $\% . F A L S E \_E \%, \% . F A L S E \_N \%, \% . S T A N D A R D \_P 1 \%$, AND $\% . S T A N D A R D \_P 2 \%$ - projection parameters

o \%.mapang\% - a value used in the GEOCOORDS.AML and UTMCOORDS.AML to make the arcs horizontal (level) when establishing label points for coordinate text placement

Output:

o PROJECTION.AML creates the \%.COVER\%_NLTRANS, $\% . C O V E R \%$ NLLAMB, \%.COVER\%_TIC83T, or \%.COVER\%_TIC83L coverage

o PROJECTION83.AML creates the \%.COVER\%_S1GRDU, $\% . C O V E R \% \_S 2 G R D U, \% . C O V E R \% \_S 3 G R D U$, and the $\% . C O V E R \% \_S 4 G R D U$ coverages

o The GENCLIP.AML and GENCLIP83.AML create the GEO_ERASE, ST_ERASE, and the ST_CLIP covers in either Lambert Conformal Conic or Transverse Mercator projections for the NAD27 or in a UTM projection for the NAD83. Both AML's run the MAPANG.AML to level the neatline

o The TRANS.AML creates \%.COVER\%_GGRIDT, \%.COVER\%_PTT, $\% . C O V E R \%$ UGRIDT, and the \%.COVER\%_S2GRDT (and other State) coverages

o The LAMBERT.AML creates \%.COVER\%_GGRIDL, \%.COVER\%_PTL, $\% . C O V E R \%$ UGRIDL, and the \%.COVER\%_S2GRDL (and other State) coverages

\section{CLIPCOV2.AML}

Function:

o Clips or erases the geogrid, State, and UTM files to specified symbol standards

o Runs the GEOCOORDS.AML that sets variables for geographic text label placement 
Global variables:

o $\quad \% . g 1 \%$ through $\% . g 8 \%$ - geographic text strings generated in the GEOCOORDS.AML. The text strings are developed using the $\% . C O V E R \%$ _GGRIDT, \%.COVER\%_GGRIDL, or \%.COVER\%_GGRD 83 coverages

o $\quad \%$.fnode $1 \%$ through $\%$.fnode $8 \%$ and $\%$.tnode $1 \%$ through $\%$.tnode $8 \%$ - label points generated in the GEOCOORDS.AML. The label points are used for text placement in the TESTPLOT.AML and ESPLOT.AML

o $\quad \% . u 1 \%$ through \%.u8\% - UTM test strings generated in the UTMCOORDS.AML. The text strings are developed using the $\% . C O V E R \%$ UTMGRID coverages

o $\quad \%$.utnode $1 \%$ through $\%$.utnode $8 \%$ and $\%$.ufnode $1 \%$ through $\%$.ufnode $8 \%$ UTM label points generated in the UTMCOORDS.AML. The UTM label points are used for text placement in the TESTPLOT.AML and ESPLOT.AML

Output:

o \%.COVER\%_GTICS - the neatline coverage and graticule ticks representing geographic coordinates

o \%.COVER\%_S1TICS, \%.COVER\%_S2TICS, \%.COVER\%_S3TICS, and $\% . C O V E R \% \_S 4 T I C S$ - representing State plane coordinates

o \%.COVER\%_UTICS - representing UTM coordinates

8. TESTPLOT.AML

Function:

o Creates a 1040 graphics file containing geographic coordinate labels and line symbology directed toward the Scitex plotter.

The TESTPLOT.AML and ESPLOT.AML require a number of variables to automatically place geographic and UTM text. These variables measure distance in map units and appear at the beginning of the geographic and UTM labeling sequences. TESTPLOT.AML also looks for conflicts between geographic and UTM text. To do this, variables are set to pinpoint the beginning and end of geographic text strings. An example is \%g5bs\%. This convoluted variable means text string g5, bottom neatline, starting point for text string. Similar variables will identify the top starting $(\% \mathrm{~g} 5 \mathrm{ts} \%)$ and ending 
points $(\% \mathrm{~g} 5$ te $\%)$ and the bottom ending point $(\% \mathrm{~g} 5 \mathrm{be} \%)$

Output:

o TESTPLOT.GRA - the ARC/INFO graphics file created in the TESTPLOT.AML

8b. ESPLOT.AML

Function:

o Creates a 1040 graphics file containing geographic and UTM coordinate labels and black symbology for State plane ticks directed toward an electrostatic plotter

Output:

o ESPLOT.GRA - the ARC/INFO graphics file created in the ESPLOT.AML

The following are the significant coverages used in the ESPLOT.AML:

o \%.COVER\%_GTICS - the neatline with ticks representing geographic coordinates

o $\%$. COVER\%_S1TICS - representing the primary State plane ticks

o \%.COVER\%_S2TICS, \%.COVER\%_S3TICS, and \%.COVER\%_S4TICS representing the secondary, tertiary, and quaternary State plane ticks

o \%.COVER\%_UTICS - representing the UTM ticks

The following final coverages may be created, depending on the projection used by the primary State and the datum selected for the graphic:

o \%.COVER\%_GPT83 - a point coverage representing the internal graticule ticks in the NAD83

o $\%$.COVER\%_PTT - a point coverage representing the internal graticule ticks in Transverse Mercator NAD27 coordinates

o \%.COVER\%_PTL - a point coverage representing the internal graticule ticks in Lambert Conformal Conic NAD27 coordinates

o \%.COVER\%_TIC27 - a point coverage representing the external graticule ticks for the NAD27 
o \%.COVER\%_TIC83 - a point coverage representing the external graticule ticks for the NAD83

9. CLEANUP.AML

Function:

o Removes all coverages, files, and global variables. 


\section{APPENDIX 3}

The following is a list of coverages and INFO files created during the base sheet plotting routines. The list provides an outline containing the name, purpose, and origin.

\section{Coverages:}

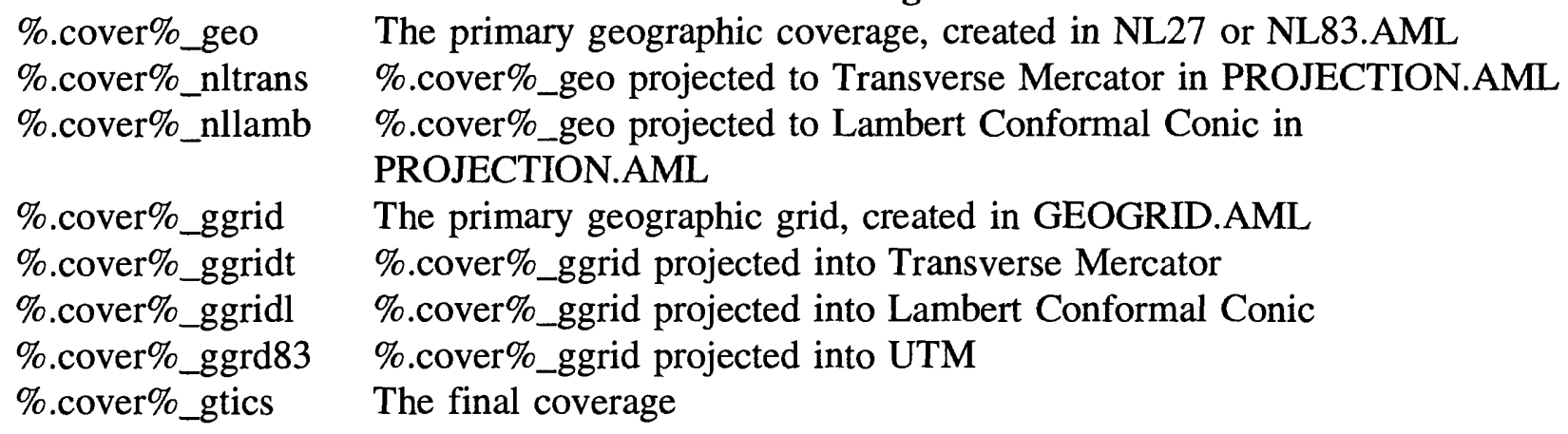

The primary geographic coverage, created in NL27 or NL83.AML $\%$.cover\%_geo projected to Transverse Mercator in PROJECTION.AML $\%$.cover\%_geo projected to Lambert Conformal Conic in PROJECTION.AML The primary geographic grid, created in GEOGRID.AML $\%$.cover\%_ggrid projected into Transverse Mercator $\%$.cover\%_ggrid projected into Lambert Conformal Conic $\% . c o v e r \%$ ggrid projected into UTM

The final coverage

\%.cover\%_ugrid

$\%$. cover\%_ugridt

$\%$.cover\%_ugridl

\section{Point Coverages}

The primary point coverage for internal geographic grid intersections created in GEOPT.AML \%.cover\%_gpt projected to Lambert Conformal Conic in LAMBERT.AML

\%.cover\%_gpt projected to Transverse Mercator in TRANS.AML $\% . c o v e r \%$ gpt projected to UTM in GEOPT.AML

The primary point coverage representing the datum created in NL27 or NL83.AML

\%.cover\%_tic representing the NAD83 in Lambert Conformal Conic

$\%$. cover\%_tic representing the NAD83 in Transverse Mercator

$\% . c o v e r \%$ tic representing the NAD27

\section{UTM Coverages}

The primary UTM grid created in UTMGRID.AML. Can be in either datum.

$\% . c o v e r \%$ ugrid projected to Transverse Mercator in TRANS.AML $\%$.cover\%_ugrid projected to Lambert Conformal Conic in

\section{LAMBERT.AML}


$\%$. cover\%_utmgrid

$\%$.cover\%_utics

$\% . c o v e r \%$ s1 grd

$\% . c o v e r \%$ s1 grdt

$\%$.cover\%_slgrdl

$\%$. cover\%_s1grdu

$\%$.cover\%_s1tics

$\%$.cover\%_s2grd

$\%$.cover\%_s2grdt

$\%$.cover\%_s2grdl

$\%$.cover\%_s2grdu

$\%$.cover\%_s2tics

$\%$.cover\%_s3grd

$\%$.cover\%_s3grdt

$\%$.cover\%_s3grdl

$\%$.cover\%_s3grdu

$\%$.cover\%_s3tics

$\%$.cover\%_s4grd

$\%$.cover\%_s4grdt

$\%$.cover\%_s4grdl

$\%$. cover\%_s4grdu $\%$.cover\%_s4tics

The product of clipping \%.cover\%_ugridt, ugridl, or ugrid in CLIPCOV.AML

The final UTM coverage

\section{State Plane Coverages}

The primary State plane grid created in STGRID.AML \%.cover\%_s1grd projected to Transverse Mercator in TRANS.AML $\%$.cover\%_slgrd projected to Lambert Conformal Conic in LAMBERT.AML

\%.cover\%_slgrd projected to UTM in PROJECTION83.AML

The final primary State plane coverage

The secondary State plane grid created in STGRID.AML $\%$.cover\%_s2grd projected to Transverse Mercator in TRANS.AML $\%$.cover\%_s2grd projected to Lambert Conformal Conic in LAMBERT.AML

\%.cover\%_s2grd projected to UTM in PROJECTION83.AML

The final secondary State plane coverage

The third State plane grid created in STGRID.AML

$\%$.cover\%_s3grd projected to Transverse Mercator in TRANS.AML $\%$. cover\%_s3grd projected to Lambert Conformal Conic in

\section{LAMBERT.AML}

\%.cover\%_s3grd projected to UTM in PROJECTION83.AML

The final tertiary State plane coverage

The fourth State plane grid created in STGRID.AML

$\%$.cover\%_s4grd projected to Transverse Mercator in TRANS.AML $\%$.cover\%_s4grd projected to Lambert Conformal Conic in LAMBERT.AML

\%.cover\%_s4grd projected to UTM in PROJECTION83.AML The final quaternary State plane coverage

\section{Clip/Erase Coverages}

$\%$.cover\%_slerase The product of clipping \%.cover\%_s1grdl, slgrdt, or s1grdu in CLIPCOV.AML

$\%$. cover\%_s2erase The product of clipping \%.cover\%_s2grdl, s2grdt, or s2grdu in CLIPCOV.AML

$\%$. cover\%_s3erase The product of clipping \%.cover\%_s3grdl, s3grdt, or s3grdu in CLIPCOV.AML

$\%$. cover\%_s4erase The product of clipping \%.cover\%_s4grdl, s4grdt, or s4grdu in CLIPCOV.AML

geo_erase

An erase cover created in the GENCLIP.AML or GENCLIP83.AML

st_erase

st_clip
An erase cover created in the GENCLIP.AML or GENCLIP83.AML A clip cover created in the GENCLIP.AML or GENCLIP83.AML 
INFO Files:

proj27.tab

Contains projection parameters for NAD27 State plane conversion

proj83.tab

Contains projection parameters for NAD83 State plane conversion 